\title{
Vulva Kanseri ve Vulvektomi Sonrası Hemşirelik Yaklaşımları
}

\author{
Vulva Cancer and Nursing Approaches After Vulvectomy

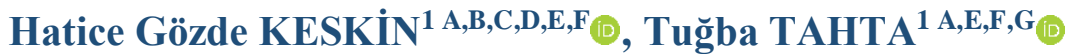 \\ ${ }^{1}$ Ankara Medipol Üniversitesi, Sağlık Hizmetleri Meslek Yüksekokulu, Ankara, Türkiye
}

\begin{abstract}
ÖZ
Vulva kanseri tüm genital kanserlerin \%4-5'ini, jinekolojik kanserlerin de \%1'ini oluşturur. Son yıllarda vulva kanseri insidansı artış göstermektedir. Vulva kanseri için tedavi ve bakımdaki önemli gelişmeler, özellikle ileri evre hastalı̆̆ı olanlar için terapötik seçenekler hakkında yeni düşünme ve araştırma yöntemleri gerektirecektir. Bu derlemenin amacı, vulva kanserinde önceden tanımlanmış cerrahi sonrası semptomların erken saptanmasını ve değerlendirilmesinin önemi anlatılmaktadır. Ayrıca vulva kanserinde kanıta dayalı semptom giderici müdahalelerin kullanımıyla hemşirelik bakımına yönelik mevcut kanıtları özetlemektir. Vulva kanserinin biyolojisi hakkındaki en son araştırmaları vurgulamak ve hasta yönetimi için daha iyi stratejilerin geliştirilmesini kolaylaştırmaktır.
\end{abstract}

Anahtar Kelimeler: Vulva, Kanser, Hemşirelik.

\section{ABSTRACT}

Vulva cancer constitutes $4-5 \%$ of all genital cancers and $1 \%$ of gynecological cancers. Recently, the incidence of vulvar cancer has been increasing. Significant advances in treatment and care for vulvar cancer will require new thinking and research methods about therapeutic options, especially for those with advanced disease. The purpose of this review is to describe the importance of early detection and evaluation of pre-defined post-surgical symptoms in vulvar cancer. In addition, the use of evidence-relieving interventions in vulvar cancer is to summarize the present for nursing care. It is to emphasize research on the biology of vulvar cancer and facilitate the development of better strategies for patient management.

Key Words: Vulva, Cancer, Nursing.

\section{GİRIŞ}

\section{VULVA KANSERI}

Vulva kanseri tüm genital kanserlerin \%4-5'ini, jinekolojik kanserlerin de \%1'ini oluşturur (1). Vulva kanseri çoğunlukla labia majörleri etkiler. Daha az sıklıkla, kanser labia minörleri, klitoris veya vajinal bezleri etkiler (2). Vulva kanseri genellikle birkaç yıl içinde yavaşça oluşur. Cildin yüzeyinde uzun süre anormal hücreler büyüyebilir. Bu duruma vulvar intraepitelyal neoplazi (VIN) denir. VIN vulva kanserine dönüştüğünde tedavi olmak çok önemlidir (3-5).

Vulva maligniteleri, özellikle son on yılda artan insidans göz önüne alındığında, ciddi bir jinekolojik sağlık endişesini temsil etmektedir. Birçok vulva kanseri başlang ıçta enflamatuar durumlar olarak yanlış teşhis edilir. Bu durum tanıyı geciktirir ve prognozu kötüleştirir (6).

Vulva kanseri en sık 65-74 yaş arası kadınlarda teşhis edilir. 40 ile 60 yaş arasındaki vakalar daha sık görülmesine rağmen, esas olarak yaşlı kadınları etkiler (7). Son yıllarda vulva 
kanseri insidansı her beş yılda ortalama \% 4,6 artmıştır; vulva kanseri 2018 yılında 1200 ölüme neden olmuştur. Amerika Birleşik Devletleri'ndeki 100.000 kadın için üç ile dört arasında tahmin edilen insidansı, son yıllarda Amerika Birleşik Devletleri'nde ve Avrupa'da artmıştır (1-8).

Vulva kanseri için spesifik bir etyolojik ajan saptanmamıştır. Bu kanserlerin \%90’1 yass1 hücreli karsinomdur. Skuamöz hücreli karsinom ve melanom yaygın alt tiplerdir. Ancak bazal hücreli karsinom gibi diğer neoplazmalar görülebilir. Serviks, vagina ve vulva embriyolojik olarak ortak kökene sahip olduğu için aynı onkojenik ajana birden fazla yanıt olduğu düşünülmektedir. Vulva kanserlerin \% 25- 40'1, vajinal kanserlerin yaklaşık \% 66's1 ve anal kanserlerin \%70-90'ı Human Papilloma Virüs (HPV) enfeksiyonu ile ilişkilidir. Buradan yola çıkarak serviks kanseri etyolojisinde rol oynayan faktörlerin vulva kanseri için de risk faktörü oluşturabileceği ileri sürülmektedir (9). HPV aşısının uygulamaya sokulmasıyla klinik çalışmalar ile vulva intraepitelyal neoplazinin ve potansiyel olarak vulva kanserinin oluşumunun azaltılmasındaki klinik etkinliğini gösterdiği bildirilmektedir (10). İmmünosupresyon, artan yaş, vulvanın prekanser koşullarına sahip olması, vulvayı içeren bir cilt hastalığının bulunması ve sigara kullanımı vulva kanseri gelişme riski taşıyan diğer tıbbi durumlardır. Teşhise yol açan semptomlar ve durumlar spesifik değildir (11).

Vulva kanseri ilk evrelerinde belirti vermeyebilir. Genel olarak vulvada yanma, ağrı, kızarıklık, kaşıntı, renk değişikliği, döküntü, siğil ve deride kalınlaşma gibi belirtilerle karşılaşılır (12). Vulvada lezyonlar veya olağandışı görünen başka herhangi bir şey gibi hastalık belirtileri olup olmadığını kontrol edilmelidir. Vulvada görülen her şüpheli lezyondan biyopsi alınarak tanı kesinleştirilmelidir. Biyopsi en az 4 mm kalınlıkta olmalıdır. Biyopsi materyalinde mutlaka hücre tipi ve invazyon derinliği bildirilmelidir. Vulva kanseri teşhis edildikten sonra, kanser hücrelerinin vulva içinde veya vücudun diğer bölgelerine yayılıp yayılmadığını bulmak için pelvik muayene, kolposkopi, sistoskopi, proktoskopi, pelvik manyetik rezonans (MRI), bilgisayarlı tomografi (CT) taraması yapılmalıdır. Vulva kanserinde güncel tedavi ilkeleri hastanın yaşına, performansına, hastalığın evresine, tümörün yaygınlığına, lenf nodu durumuna, lezyonun lokalizasyonuna göre belirlenir (13).

Vulva kanseri tedavi şekilleri cerrahi, preoperatif ve postoperatif radyoterapi ve kemoterapiyi içerir. Tedavide amaç kadının cinsel işlevini kaybetmeden tüm kanseri ortadan kaldırmaktır. Radyasyon tedavisi, kanser hücrelerini öldürmek veya büyümelerini önlemek için yüksek enerjili x-1şınları veya diğer radyasyon türlerini kullanılan bir kanser tedavisidir. Kemoterapi, hücreleri öldürerek veya hücrelerin bölünmesini durdurarak kanser hücrelerinin büyümesini durdurmak için ilaçlar kullanan bir kanser tedavisidir. Son 20 yılda vulva kanserinin cerrahi tedavisinde önemli ilerlemeler kaydedilmiştir. Geniş lokal eksizyon, erken evre hastalık için radikal vulvektominin yerini almıştır. Bu modifikasyonlar, morbiditeyi önemli ölçüde azaltırken onkolojik sonuçları korumuştur (11-14).

Vulva kanserinde ölüm oranları yaşla birlikte artmaktadır. Ölüm sayısı 2012-2016 y1lları arasında yılda 100.000 kadın başına 0,5'tir. Göreceli sağkalım istatistikleri, kanser teşhisi konan hastaların sağkalımı ile aynı yaş, ırk ve cinsiyette olan ve kanser teşhisi konmamış genel popülasyondaki insanların sağkalımı ile karşılaştırılmaktadır. Hayatta kalma istatistikleri büyük insan gruplarına dayandığından, bireysel bir hastaya ne olacağını tam olarak tahmin etmek için kullanılamaz. Hiçbir hasta tamamen birbirine benzemez ve tedavi ve tedaviye yanıtlar büyük ölçüde değişebilir (7). 


\section{HEMŞIRELİK YAKLAŞIMLARI}

\section{Sağlık Eğitimi ve Danışmanlık}

Kadınların vulva kanserinden korunması için kendi kendine vulva muayenesi (KKVM) yapmaları konusunda eğitilmelidirler. Ayrıca vulva kanseri olan kadınlarda olası değişiklikleri tanımlamak için vulvanın kendi kendine muayenesine aşina olmalıdır. Yeterli ışık kaynağı ve iyi konumlandırılmış bir ayna yardımıyla cilt kızarıklığı, şişme, koku, akıntı değerlendirilmelidir (15).

Vulva cerrahisinden sonra kadınlar sıklıkla semptomlar ve ilgili sıkıntı yaşarlar. Semptomlar üç tipte kategorize edilebilir: bunlar yara ile ilişkili semptomlar (örn. Şişme, ağrı vb.), psikososyal semptomlar (örn. yorgunluk, suçluluk vb.) ve günlük yaşamdaki zorluklar (örn. oturma sirasında vb.) (16). İnsizyon ve genital bölge için mevcut bakım, yıkama alışkanlıkları ve tercih edilen bakım ürünleri değerlendirilmelidir. Genital bölge günde bir kez temiz suyla temizlemelidir. Sünger, firça, sabun, duş jeli, köpük banyosu, deodorant, bebek mendili, bitkisel kullanımdan kaçınılması konusunda eğitilmelidir. Yaraya bağlı ağrı durumunda rahat kıyafetler ve yumuşak koltuklar önerilir. Ağrı azaltmanın tamamlayıcı yöntemi olarak müzik terapisi önerilebilir (15-17). Giysilerle ilgili zorluklar olması durumunda uygun giyinilmesi gerektiği, rahat, beyaz ipek veya pamuklu iç çamaşırı, tayt yerine rahat pantolon veya etek önerilmelidir. İç çamaşırı olmadan uzun etek giymek ve iç çamaşırı olmadan uyumak, özellikle evde rahat olabilir. Genel olarak, bireysel sorunlar değerlendirilmelidir. Uygun çözümler hasta ile tartışılmalıdır (15-18).

Klinik araştırmalardan elde edilen sonuçlar ile HPV aşı programının, HPV ile ilişkili prekanserlerin ve kanserlerin oluşumunu azaltma potansiyeline sahip olduğunu göstermektedir. Klinisyenler ve hemşireler, tüm HPV ile ilgili hastalıkların oluşumunu azaltmak için 9 ila 45 yaş arasındaki tüm kadınlara HPVaşısını önermelidir (10-19).

Belirsizlik nedenleri araştırılmalı ve hasta tanı, tedavi ve bakıma bağlı olarak yeterli bilgi almalıdır. Bireysel çözümler ve başa çıkma stratejileri belirlenmelidir (20).

\section{Hastalık Algısı ve Öz Bakım Gücü}

Öz bakım gücü, bireylerin sağlık durumlarının tıbbi, rol ve duygusal yönetimini ele almak için üstlendiği görevler olarak tanımlanabilir. Semptomlar (yaraya bağlı, psikososyal ve günlük yaşamdaki zorluklar) hastalık algısını ve öz bakım gücünü olumsuz etkileyebilir (4).

Zhang ve arkadaşları (2006) kanser tanılı olup iyileşen hastaların hastalık algısını inceledikleri çalışmada, jinekolojik kanserli hastaların olumsuz hastalık algısının yüksek olduğunu saptamıştır (21). Küçükkaya ve Erçel (2019) yaptıkları çalışmada jinekolojik kanserli hastaların hastalığı endişe verici olarak algılama düzeyi yüksek ve kişisel kontrol algılama düzeyi düşük bulmuştur (22). Süt'ün (2017) jinekolojik cerrahi operasyon öncesi hastaların hastalık algıları üzerine etkili faktörleri incelediği çalışmada, kanserli hastaların hastalığın negatif sonuçlarına ilişkin algılarının yüksek olduğu bulunmuştur (23).

Literatür bulguları jinekolojik kanserli hastaların öz bakım gücü ve hastalık algılarında benzerlik göstermektedir. Bu sonuçlar doğrultusunda; hastalığın sonucuna, kişisel kontrole, tedavinin yararına, semptom şiddetine, endişeye, hastalığı anlama düzeyine, emosyonel duruma bağlı olarak olumsuz inançları yüksek olan vulva kanserli hastaların bakımından sorumlu olan 
hemşirelerin, bireylerin öz bakımını arttırmaya yönelik olumlu hastalık algısı geliştirmesi ve öz bakım gücünü yükseltmesi gerekmektedir. Ayrıca hem hastalık algısını hem de öz bakım gücünü etkileyen kanser evresi ve metastaz durumuna yönelik olarak erken evrede hastalığın tanımlanması amacıyla bu alanda uzmanlaşan hemşirelerin aktif katılımının sağlanması önerilmektedir. Hastalık algısını ve öz bakım gücünü etkileyen faktörlerin belirlenmesi ve bu faktörlerin ortadan kaldırılması veya etkilerinin azaltılması, bireyler ve aileler için eğitimlerin planlanması ve bireylerin öz bakım gücünün artırılmasına yönelik müdahalelerin desteklenmesi önemli hemşirelik müdahaleleridir.

\section{Cinsel Bakım ve Ĕgitim}

Jinekolojik kanser hastalarında cinsel işlevsellik önemli ölçüde etkilenir. Tedavi yöntemleri jinekolojik kanserli hastaların cinsel işlevlerini etkilemektedir. Bununla birlikte, çoğu hastaya farklı tedavi yöntemleri uygulanmaktadır ve farklı rejimlerin etkileri değerlendirilmemiştir. Ayrıca vulva, uterus ve over kanseri olan hastaların cinsel işlevleri hakkında dramatik veri eksikliği vardır. Vulva kanseri kadın cinsel organının dış yüzeyinde meydana gelen bir kanser tipidir. Genellikle geniş cerrahi eksizyon, hemi veya total vulvektomi ile tedavi edilir. Lenf düğümlerinin pozitif metastazlarında kemoterapi ve radyoterapi kullanılır. Çok az çalışma vulva kanseri olan hastalarda cinsel işlevselliği değerlendirmiştir (24-25). Kısmi veya total vulvektomi iyileşme sürecinde fibrozise bağlı vulva deformasyonuna neden olabilir. Genel olarak, önemli cinsel bozukluklar, tedaviden sonraki ilk yıl boyunca, özellikle cinsel uyarılma ve orgazm ile ilgili daha kalıcı problemlerle daha belirgindir (26).

Bazı hastalar vajinal stenoz yaşar ve cinsel ilişkiyi sağlamak için ek plastik cerrahi geçirebilirler. Potansiyel vulva şekil bozukluğunun yanı sıra, çoğu hasta cinsel uyarılma sırasında genital semptomların algılanmasında azalma yaşar (26). Ancak, bu alandaki bakım ve müdahaleler hala ihmal edilmektedir. Cinsellik nadiren sağlık uzmanları tarafindan ele alınmakta ve cinsel işlev nadiren bir tedavi sonucu olarak değerlendirilmektedir. Çoğu sağlık uzmanı, jinekolojik kanserli kadınların çoğunun cinsel problemler yaşadığına inandıkları halde, sadece \%20-35'i hastalarla cinsel sorunları tartışmıştır (28).

Vulva kanserinde cinsel eğitimin amacı kadının hastalığını kabul etmesini artırmak, bu durum ile ilişkili psikososyal morbiditeyi azaltmak, cinsellik hakkındaki yanlış anlamaların ve yanlış bilgilerin açıklığa kavuşturulmasına yardımcı olmak ve tecrit duygularını azaltmaktır (28). Hastalığın vücut imajı ve cinsel yaşam üzerindeki etkisi, vücudun öznel anlamı ve cinsellik hasta ile tartışılmalıdır. Gerekirse, vücut imajını tartışmak için başka randevular düzenlenmelidir. Hasta psikososyal ve psikoseksüel destek ve rekonstrüktif cerrahi olasıllğ 1 hakkında bilgi almalıdır (20).

\section{Psikolojik Sonuçlar ve Yaşam Kalitesi}

Vulva kanseri hastaları ameliyatın büyüklügüne bağlı olmakla birlikte bireysel fiziksel ve psikolojik faktörlerden etkilenir. Hastalı̆̆ın standart tedavisi olan radikal vulvektomi, geniş deformiteler ve psikoseksüel sorunlara dolayısıyla yaşam kalitesinin azalmasına neden olabilir (29). Hastayı ve partnerini şekil bozukluğu, eşlerin yakınlık ve ilişki kaygısı dahil olmak üzere çeşitli psikososyal faktörler etkileyebilir (26).

Evre IV hastalar için eğer mesane ve rektuma da yayılma varsa radikal vulvektomiye ek olarak pelvik egzantrasyon (vajina, uterus, fallop tüpleri, mesane ve rektumun çıkarılması) 
uygulanır. Hastada stoma ve üriner yol (ostomi) açılır. Bu cerrahi hastada önemli derecede psikolojik sorun yaratır ve yaşam kalitesi etkilenir. Yaşam kalitesindeki bozukluklar tedavi sonucunu etkilemektedir. Vulva kanserinde psikolojik tedavi, tedavinin bütünleyici ve ayrılmaz bir bölümü olup, hastalığın fiziksel tedavisini tamamlayıcıdır. Psikolojik tedavi girişimleri, danışmanlık, eğitim veya psikoterapötik yollarla baş etme davranışını geliştirmek için uygulanır. Hasta kızgınlık, öfke, suçluluk gibi duygu ve tepkilerin rahat ifade edilmesi için ve hastalıkla ilgili düşüncelerini anlatması için cesaretlendirilmelidir (27-30).

\section{Taburculuk Öncesi Eğitim Gereksinimleri ve Taburculuk Eğitimi}

Taburculuk eğitimi, hastanın durumu ameliyat sonrası stabil hale geldiğinde ve hasta hastaneden çıkmadan önce başlatılır ve sürdürülür. Hasta eğitiminin çoğu alanlarında yeni teknolojiler geliştirilmesine karşın, yazılı eğitim materyalleri hasta eğitimde önemli bir yer tutmaktadır. Semptom günlüğü, semptomları tanımlamak, değerlendirmek, gözlemlemek ve yönetmek için hastalar için tavsiye edilir (16). Bununla birlikte hastanın okuma-yazma bilmesi ile yazılı eğitim materyallerinden yararlanması arasında pozitif bir ilişki vardır $(30,31)$.

Cerrahi girişime bağlı korku ve kaygıya ek olarak cinsel fonksiyon, doğurganlığı yitirme, kadınlık rolünü kaybetme, beden imajının değişmesi ve ileostomi bakımına ilişkin farklı endişeler de yaşayabilecekleri göz önünde bulundurularak, hemşirelerin bu hastaların öğrenim gereksinimlerini saptama ve öğrenim gereksinimleri doğrultusunda hastaları ayrıntılı olarak bilgilendirme konusunda özel önem vermeleri gerektiği düşünülmektedir (4).

\section{SONUÇ}

Birincil rolü bakım sağlamak olan hemşireler, vulva kanseri hastalarını kaliteli ve sürekli bakım için iyileştirme müdahalelerinde yer almalıdır. Hemşireler hastanın potansiyel gücünü kullanmasını sağlamalıdır.

\section{Çıkar Çatışması}

Yazarlar arasında çıkar çatışması yoktur.

\section{KAYNAKLAR}

1. DeSantis, C.E., Siegal, R., Ma, J., Zou, Z., \& Jemal, A. (2018). Cancer treatment and survivorship statistics. American Cancer Society. CA Cancer J Clinic, 64, 252-27.

2. Taşkın, L. (ed.) (2016). Doğum ve Kadın Sağlı̆̆ Hemşireliği. Sistem Ofset Yayıncılık, Ankara.

3. Judson, P.L., Habermann, E.B., Baxter, N.N., Durham, S.B., \& Virnig, B.A. (2006). Trends in the incidence of invasive and in situ vulvar carcinoma. Obstet Gynecol, 107(5), 1018e 22

4. Zweizig, S., Korets, S., \& Cain, J.M. (2014). Key concepts in management of vulvar cancer. Best Pract Res Clin Obstet Gynaecol, 28, 959-966.

5. Siegel R.L., Miller K.D., \& Jemal A. (2017). Cancer Statistics. CA Cancer J Clin, 67:730 . 
6. Tan, A., Bieber, A.K., Stein, JA., \& Pomeranz, M.K. (2019). Diagnosis and management of vulvar cancer: A review. Journal of the American Academy of Dermatology. doi:10.1016/j.jaad.2019.07.055

7. National Cancer Institute-Surveillance, Epidemiology and End Results. (2016). Cancer Stat Facts: Vulvar Cancer. https://seer.cancer.gov/statfacts/html/ovary.html. Erişim: 30.10.2019.

8. Hampl, M., Deckers-Figiel, S., Hampl, J.A., Rein, D., \& Bender, H.G. (2008). New aspects of vulvar cancer: changes in localization and age of onset. Gynecol Oncol, 109(3), 340e5.

9. Shindo, M., Ueda, Y., Kimura, T., \& Matsuo, K. (2017). Diagnosis and management of vulvar cancer, in: D. Shoupe (Ed.), Handbook of Gynecology, 1st edit, New York. pp. 789-806.

10. Francis, J.A., Eiriksson, L., Dean, E., Sebastianelli, A., Bahoric, B., \& Salvador, S.(2019). Management of squamous cell cancer of the vulva. Journal of Obstetrics and Gynaecology Canada, 41(1), 102-115.

11. Van der Zee, A.G.J., Oonk, MH., De Hullu, J.A., Ansink, AC., Vergote, I., \& Verheijen, RH. (2008). Sentinel node dissection is safe in the treatment of early-stage vulvar cancer. J Clin Oncol Off J Am Soc Clin Oncol, 26(6), 884e91.

12. Reade, C.J., Eiriksson, L.R., \& Mackay, H. (2014). Systemic chemotherapy in squamous cell carcinoma of the vulva: Current status and future directions. Gynecol Oncol, 132, 780-789.

13. Covens, A., Vella, E.T., Kennedy, E.B., Reade, C.J., Jimenez, W., \& Le, T. (2015). Sentinel lymph node biopsy in vulvar cancer: Systematic review, meta-analysis and guideline recommendations. Gynecol Oncol, 137, 351-361.

14. Moore, D.H., Koh, W.J., Mc Guire, W.P., \& Wilkinson, E.J. (2009). Chapter 20: vulva. In: Barakat, R.R., Markman, M., Randall, M.E., editors. Principles and Practice of Gynecologic Oncology. Baltimore: Lippincott Williams \& Wilkins;p. 555-90.

15. Kobleder, A., Raphaelis, S., Glaus, A., Fliedner, M., Mueller, M.D., Gafner, D., et al. (2016). Recommendations for symptom management in women with vulvar neoplasms after surgical treatment: An evidence-based guideline. European Journal of Oncology Nursing, 25, 68-76. doi:10.1016/j.ejon.2016.10.003

16. Senn, B., Mueller, M.D., Hasenburg, A., Blankenstein, T., Kammermann, B., Hartmann, A., et al. (2012). Development of a postsurgical patient-reported outcome instrument for women with vulvar neoplasia. Oncol. Nurs. 39 (6), E489eE498. http://dx.doi.org/10.1188/ 12.ONF.E489-E498.

17. Belhadj, H., Berek, J., Bermudez, A., Bhatla, N., Denny, L., Fujiwara, K., et al. (2014). FIGO staging for carcinoma of the vulva, cervix, and corpus uteri. Int. J. Gynaecol. obstet. 125 (2), 97e98. http:// dx.doi.org/10.1016/j.ijgo.2014.02.003

18. Sheldon, L.K., Swanson, S., Dolce, A., Marsh, K., \& Summers, J. (2008). Putting evidence into practice: evidence-based interventions for anxiety. Clin. J. Oncol. Nurs. 12 (5), 789e797. http://dx.doi.org/10.1188/08.CJON.789-797

19. Herrero, R., Hildesheim, A., Rodriguez, A.C, Wacholder, S., Bratti, C., Solomon, D., et al. (2008). Rationale and design of a community-based double-blind randomized clinical trial of an HPV 16 and 18 vaccine in Guanacaste, Costa Rica Vaccine, 26, 47954808

20. Beatty, LJ., Koczwar,a B., Rice, J., \& Wade, TD. (2010). A randomised controlled trial to evaluate the effects of a self-help workbook intervention on distress, coping and quality of life after breast cancer diagnosis. Med. J. 193 (5), S68eS73.

21. Zhang, N., Fielding, R., Soong, I., Chan, KK., Tsang, J., Lee, V. et al. (2006). Illness perceptions among cancer survivors. Supportive Care in Cancer, 24(3), 1295-304. 
22. Küçükkaya, B., \& Erçel, Ö. (2019). Jinekolojik kanserli hastalarda hastalık algısının özbakım gücüne etkisi. Ege üniversitesi hemşirelik fakültesi dergisi. 35(3), 137-145.

23. Süt, H.K. (2017). Jinekolojik Cerrahi Operasyon Öncesi Hastaların Hastalık Algıları Üzerine Etkili Faktörler. Bakırköy Tip Dergisi, 13, 83-90.

24. Green, M.S., Naumann, RW., Elliot, M., Hall, J.B., Higgins, R.V., \& Grigsby. J.H. (2000). Sexual dysfunction following vulvectomy. Gynecol Oncol, 77, 73-7.

25. Thuesen, B., Andreasson, B., \& Bock, J.E. (1992). Sexual function and somatopsychic reactions after local excision of vulvar intra-epithelial neoplasia. Acta Obstet Gynecol Scand, 71, 126-8.

26. Jensen, P.T. (2007). Gynaecological cancer and sexual functioning: Does treatment modality have an impact? Sexologies, 16(4), 279285. doi:10.1016/j.sexol.2007.06.010

27. Chow, K.M., Chan, C.W.H., \& Chan, J.C.Y. (2012). Effects of psychoeducational interventions on sexual functioning, quality of life and psychological outcomes in patients with gynaecologcal cancer. JBL libraryof systematic reviews. 10(58), 40774164.

28. Southard, N.Z., \& Keller, J. (2009). The importance of assessing sexuality: A patient perspective. Clin J Oncol Nurs, 13(2), 213-7.

29. Köse, F., \& Karabük, E. (2017). Surgical management of vulvar carcinoma. Turkiye Klinikleri J Gynecol Obst-Special Topics, 10(2), 203-9.

30. Şirin, A., Kavlak, O. (ed.) (2015). Kadın Sa ğğğ , Nobel Yayıncılık, İstanbul.

31. Uzun, O., Ucuzal, M., \& İnan, G. (2011). Post-Discharge Learning Needs of General Surgery Patients. Pak J Med Sci, 27(3), 634-637.

32. Beck, S. L., Brant, J. M., Donohue, R., Smith, E. M. L., Towsley, G. L., Berry, P. H., et al. (2016). Oncology nursing certification: relation to nurses' knowledge and attitudes about pain, patient-reported pain care quality, and pain outcomes. Oncol Nurs Forum, 43 (1), 67-76. 